\title{
PRODUTIVIDADE DO MELOEIRO SOB LÂMINA DE IRRIGAÇÃO E ADUBAÇÃO POTÁSSICA ${ }^{1}$
}

\author{
ANTONIO E. C. SOUSA ${ }^{2}$, FRANCISCO M. L. BEZERRA ${ }^{3}$, CARLOS H. C. DE SOUSA ${ }^{4}$, \\ FRANCISCO S. S. DOS SANTOS
}

\begin{abstract}
RESUMO: Teve-se o objetivo de avaliar o efeito de quatro lâminas de irrigação e quatro doses de potássio aplicadas por irrigação localizada na produtividade do híbrido Gold Mine AF 10.00 do melão Amarelo (Cucumis melo L.). O experimento foi conduzido no Câmpus do Pici da Universidade Federal do Ceará. O delineamento experimental utilizado foi em blocos casualizados, com parcelas subdivididas, em esquema fatorial $4 \times 4$, onde o primeiro fator correspondeu às lâminas de irrigação, e o segundo, às doses de potássio, em quatro repetições. $\mathrm{O}$ fator lâmina de irrigação apresentou efeito altamente significativo sobre a produtividade do melão, enquanto a adubação potássica e a interação entre os fatores não foram significativas. A produtividade de frutos aumentou de forma linear com a lâmina de água aplicada, tendo sido maximizada $\left(34,8 \mathrm{Mg} \mathrm{ha}{ }^{-1}\right)$, para a lâmina de $795 \mathrm{~mm}$ (150 \% da evaporação no tanque Classe "A"), sendo que a amplitude foi superior a $16 \mathrm{Mg} \mathrm{ha}^{-1}$. $\mathrm{O}$ incremento observado na massa de fruto entre a menor e a maior lâmina de água aplicada foi de $82 \%$.
\end{abstract}

PALAVRAS-CHAVE: Cucumis melo, lâmina de irrigação, fertirrigação.

\section{MELON PRODUCTION UNDER EFFECT OF IRRIGATION BLADES AND POTASSIUM FERTILIZATION}

\begin{abstract}
The main goal of this work was to evaluate the effect of the application of the four water depths and four levels of potassium fertilization applied thought drip irrigation on the yield and quality of Yellow melon (Cucumis melo L.), group Gold Mine AF 10.00. The study was carried at the Pici Campus of Ceará Federal University from Brazil. A randomized block design with two factors and four repetitions was used. The first factor represented the water depths $(50 ; 75 ; 100$ and $150 \%$ of the Class A pan evaporation) and the second factor represented the levels of potassium fertilization $\left(150 ; 225 ; 300\right.$ and $\left.450 \mathrm{~kg} \mathrm{ha}^{-1}\right)$. The results showed that water depths linearly affected crop productivity, while Potassium fertilization and the iteration between both factors were not significant. Maximum fruit yield $\left(35 \mathrm{Mg} \mathrm{ha}^{-1}\right)$ was obtained applying $795 \mathrm{~mm}$ of water $(150 \%$ of the Class A pan evaporation). Fruit mass increased about $82 \%$ with the amount of water applied, while the yield increased more than $16 \mathrm{Mg} \mathrm{ha}^{-1}$.
\end{abstract}

KEYWORDS: Cucumis melo, irrigation depths, fertigation.

\section{INTRODUÇÃO}

O melão (Cucumis melo, L.) é a oitava hortaliça de fruto mais produzida no mundo e situa-se entre as dez mais exportadas, com mercado internacional estimado em mais de 1,6 milhão de toneladas por ano (CARVALHO, 2006). Das espécies olerícolas, o melão possui uma significativa expressão econômica e social, especialmente no Nordeste do Brasil. A produção brasileira de melão está concentrada em duas regiões do Nordeste, as quais, no conjunto, são responsáveis por quase 95\%

\footnotetext{
${ }^{1}$ Trabalho extraído da dissertação de mestrado do primeiro autor da UFC.

${ }^{2}$ Tecnólogo em Recursos Hídricos/Irrigação, Doutorando em Engenharia Agrícola, Universidade Federal de Campina Grande, Campina Grande - PB, Fone (0XX88) 9238-2852, evami@ibest.com.br

${ }^{3}$ Eng $^{\mathrm{o}}$ Agrônomo, Prof. Dr., Departamento de Engenharia Agrícola, UFC, Fortaleza - CE.

${ }^{4}$ Tecnólogo em Recursos Hídricos/Irrigação, Doutorando em Engenharia Agrícola, UFC, Fortaleza - CE.

${ }^{5}$ Tecnólogo em Recursos Hídricos/Irrigação, Coordenador do Distrito de Irrigação Tabuleiros de Russas, Russas - CE. Recebido pelo Conselho Editorial em: 5-11-2007

Aprovado pelo Conselho Editorial em: 17-3-2010
} 
da produção desta hortaliça, onde é possível obter produtividades acima de $40 \mathrm{Mg} \mathrm{ha}^{-1}$ (SOARES, 2001).

O Nordeste possui condições edafoclimáticas altamente favoráveis para a produção de melão, como a constância do calor, alta luminosidade e baixa umidade relativa do ar. Por ser cultivada no período seco, a irrigação é prática essencial para a produção comercial da cultura. Apesar disso, a irrigação na região ainda carece de estudos para manifestar sua total potencialidade, necessitando de melhor controle quanto à quantidade de água a ser aplicada, à frequência e ao momento crítico de irrigação.

$\mathrm{Na}$ região, são cultivadas praticamente todas as variedades de melão, com destaque para os melões do grupo inodoros. Atualmente, tem-se dado mais importância aos melões nobres, muito competitivos, apresentando alto potencial comercial e alta lucratividade, sendo uma cultura exigente que necessita receber quantidade de nutriente e água adequada para produção de frutos com características desejadas. Apesar da importância do meloeiro para o País, e sobretudo para a região Nordeste, a produtividade dessa cultura é muito variável entre os produtores e, na maioria das vezes, baixa em relação ao potencial produtivo da cultura. Isso mostra que há necessidade de pesquisas para definir as melhores tecnologias de adubação, de irrigação e de manejo da cultura capazes de aumentar a produtividade e a qualidade dos frutos, fazendo com que o produto seja mais competitivo nos mercados nacional e internacional. Dentre as tecnologias aplicadas no setor produtivo para aumentar o rendimento das culturas, destacam-se a irrigação localizada e a fertirrigação (OLIVEIRA et al., 2008).

Os sistemas de exploração agrícola predominantes nas áreas irrigadas de melão do Estado do Ceará geralmente aplicam água em excesso, esperando que, com maior oferta hídrica, as plantas aumentem a produtividade; entretanto, o que acarreta são os incrementos nos custos de produção, lavagem de nutrientes para fora do alcance da zona radicular das plantas e maior risco de doenças.

Além do manejo correto da irrigação, o melão é altamente exigente com relação às características do solo, sendo as propriedades físicas, químicas e biológicas de grande importância na produção e qualidade dos frutos. Uma baixa produtividade pode estar relacionada a vários fatores, entre os quais, a inadequada prática de calagem e adubação (VASQUES, 2003).

Geralmente, as quantidades aplicadas de fertilizantes não atendem às necessidades nutricionais da planta. $\mathrm{O}$ desconhecimento da fertilidade do solo cultivado e, principalmente, da exigência nutricional da planta leva a práticas de manejo inadequadas, que afetam o crescimento e a produção do meloeiro.

Dentre os nutrientes essenciais, o potássio ocupa lugar de destaque, face à deficiência deste nutriente na maioria dos solos do Nordeste e por ser um nutriente com diversos papéis no metabolismo vegetal. Atua como ativador enzimático de processos responsáveis pela síntese e degradação de compostos orgânicos e participa no processo de abertura e fechamento das células estomatais, síntese de proteína, composição da parede celular e balanço entre cátions e ânions (NACHTIGALL \& RAIJ, 2005; MALAVOLTA, 2005). É requerido em larga quantidade pelas culturas, sendo o cátion mais abundante nos vegetais, afetando o rendimento e a qualidade dos produtos colhidos (DALIPARTHY et al., 1994).

Diante do exposto, o objetivo do trabalho foi avaliar lâminas de irrigação, baseada na evaporação do tanque Classe "A", e adubação potássica sobre o rendimento da cultura do melão, utilizando irrigação localizada do tipo gotejamento.

\section{MATERIAL E MÉTODOS}

O experimento foi conduzido na área experimental do Câmpus do Pici da Universidade Federal do Ceará, Fortaleza - CE, localizado nas coordenadas 343'35' de latitude sul e 38 32'35', de longitude oeste de Greenwich, a uma altitude de 19,5 m. O clima da região é considerado como tropical chuvoso com precipitação de verão-outono, do tipo Aw' pela classificação de Köeppen. A média anual de precipitação é de $1.523 \mathrm{~mm}$, a evapotranspiração potencial é de $1.747,2 \mathrm{~mm}$, a 
temperatura média anual igual a $26,9{ }^{\circ} \mathrm{C}$ e a umidade relativa de $69 \%$. O solo da área é classificado como Argissolo Vermelho-Amarelo de textura francoargiloarenosa.

As características físico-hídricas da área foram determinadas no Laboratório de Solos e Água do Departamento de Ciências do Solo, que faz parte do Centro de Ciências Agrárias da Universidade Federal do Ceará, a partir de amostras coletadas nas profundidades de 0-0,2 e 0,2$0,4 \mathrm{~m}$, e encontram-se na Tabela 1 .

TABELA 1. Características físico-hídricas do solo da área experimental nas profundidades de 0$0,20 \mathrm{~m}$ e $0,20-0,40 \mathrm{~m}$. Physical-Hydric characteristics of the soil from the experimental area in the depths of $0-0.20 \mathrm{~m}$ and $0.20-0.40 \mathrm{~m}$.

\begin{tabular}{lcc}
\hline \multirow{2}{*}{ Características } & \multicolumn{2}{c}{ Profundidade $(\mathrm{m})$} \\
\cline { 2 - 3 } & $0-0,20$ & $0,20-0,40$ \\
\hline Físico-hídricas & & 370 \\
Areia grossa $\left(\mathrm{g} \mathrm{kg}^{-1}\right)$ & 240 & 390 \\
Areia fina $\left(\mathrm{g} \mathrm{kg}^{-1}\right)$ & 80 & 90 \\
Silte $\left(\mathrm{g} \mathrm{kg}^{-1}\right)$ & 110 & 150 \\
Argila $\left(\mathrm{g} \mathrm{kg}^{-1}\right)$ & 60 & 70 \\
Argila natural $\left(\mathrm{g} \mathrm{kg}^{-1}\right)$ & 45 & 53 \\
Grau de floculação $\left(\mathrm{g} 100^{-1} \mathrm{~g}^{-1}\right)$ & Francoarenosa & Francoarenosa \\
Características texturais & & \\
Densidade $\left(\mathrm{kg} \mathrm{dm}^{-3}\right)$ & 1,47 & 1,50 \\
solo & 2,60 & 2,59 \\
partículas & 0,187 & 0,182 \\
Capacidade de campo $\left(\mathrm{m}^{-3} \mathrm{~m}^{-3}\right)$ & 0,560 & 0,074 \\
Ponto de murchamento permanente $\left(\mathrm{m}^{-3} \mathrm{~m}^{-3}\right)$ & 0,430 & 0,386 \\
Umidade de saturação $\left(\mathrm{m}^{-3} \mathrm{~m}^{-3}\right)$ & & \\
\hline
\end{tabular}

O delineamento experimental utilizado foi em bloco inteiramente casualizado, com parcelas subdivididas (split-plot), com quatro repetições, sendo as lâminas de irrigação localizadas nas parcelas e os níveis de potássio dispostos nas subparcelas. As lâminas de irrigação $\left(\mathrm{L}_{1}, \mathrm{~L}_{2}, \mathrm{~L}_{3}, \mathrm{~L}_{4}\right)$, tratamento primário, corresponderam a 50; 75; 100 e $150 \%$ da evaporação diária no tanque Classe "A" (ECA, mm dia $\left.{ }^{-1}\right)$, e as doses de potássio $\left(\mathrm{K}_{1}, \mathrm{~K}_{2}, \mathrm{~K}_{3}, \mathrm{~K}_{4}\right)$, tratamento secundário, corresponderam a 50; 75; 100 e $150 \%$ da recomendação sob análise de fertilidade do solo segundo FERNANDES (1993).

O experimento foi conduzido no período seco, de setembro a dezembro de 2005 , tendo sido utilizado o híbrido Gold Mine AF 10.00, melão do tipo amarelo (Cucumis melo L.). A parcela experimental ocupou uma área total de $165 \mathrm{~m}^{2}$ (11 x $\left.15 \mathrm{~m}\right)$, sendo constituída por cinco fileiras de $15 \mathrm{~m}$ de comprimento, espaçadas de 2,0 m entre linhas e 0,50 m entre plantas. Em cada parcela, foi aplicado um nível de irrigação com base na evaporação do tanque Classe "A", enquanto nas subparcelas foram aplicadas as doses de potássio.

O solo foi preparado de forma convencional, constando de aração com arado de disco, seguida de gradagem cruzada. $\mathrm{O} \mathrm{pH}$ foi corrigido com aplicação de $3,5 \mathrm{Mg} \mathrm{ha}^{-1}$ de calcário calcítico. Quinze dias antes do transplantio, foram abertas as covas no espaçamento de $2 \mathrm{~m}$ entre linhas e $0,5 \mathrm{~m}$ entre covas na linha, onde foi realizada a adubação pré-plantio. Foram aplicados $15 \mathrm{Mg} \mathrm{ha}^{-1}$ do adubo orgânico Polifértil, $190 \mathrm{~kg} \mathrm{ha}^{-1}$ de fósforo e $150 \mathrm{~kg} \mathrm{ha}^{-1}$ de FTE-BR 12.

A irrigação foi realizada por gotejamento, com uma linha lateral, espaçada a cada $2 \mathrm{~m}$, por fileira de plantas. O sistema era composto por vinte linhas laterais de polietileno de $15 \mathrm{~m}$ de comprimento e diâmetro nominal de $16 \mathrm{~mm}$, tendo no início da linha lateral um registro para controle das lâminas de água aplicadas nos tratamentos. Os gotejadores eram do tipo Katif, autocompensantes, espaçados a cada $0,5 \mathrm{~m}$, com vazão média de $2,75 \mathrm{~L} \mathrm{~h}^{-1}$, para uma pressão de serviço de $150 \mathrm{kPa}$. 
TABELA 2. Características químicas do solo da área experimental nas profundidades de 0-0,20 m e $0,20-0,40 \mathrm{~m}$. Chemical characteristics of the soil from the experimental area in the depths of 0-0.20 $\mathrm{m}$ and $0.20-0.40 \mathrm{~m}$.

\begin{tabular}{lcc}
\hline \multirow{2}{*}{ Características } & \multicolumn{2}{c}{ Profundidade $(\mathrm{m})$} \\
\cline { 2 - 2 } Química & $0-0,20$ & $0,20-0,40$ \\
Complexo sortivo $\left(\mathrm{cmol}_{\mathrm{c}} \mathrm{kg}^{-1}\right)$ & & \\
Cálcio & 1,00 & 0,90 \\
Magnésio & 0,80 & 0,80 \\
Sódio & 0,17 & 0,19 \\
Potássio & 0,13 & 0,11 \\
Hidrogênio & 1,91 & 1,71 \\
Alumínio & 0,40 & 0,60 \\
Soma de bases & 2,10 & 2,00 \\
Capacidade de troca de cátions & 4,40 & 4,30 \\
Saturação de bases $(\%)$ & 48 & 46 \\
Percentagem de sódio trocável & 4 & 4 \\
\hline Outras Determinações & & 4,5 \\
pH em água & 4,7 & 0,40 \\
Condutividade elétrica $\left(\mathrm{dS} \mathrm{m}{ }^{-1}\right)$ & 0,40 & 4,68 \\
Carbono orgânico $\left(\mathrm{g} \mathrm{kg}^{-1}\right)$ & 5,04 & 0,48 \\
Nitrogênio $\left(\mathrm{g} \mathrm{kg}^{-1}\right)$ & 0,51 & 8,07 \\
Matéria orgânica $\left(\mathrm{g} \mathrm{kg}^{-1}\right)$ & 8,69 & 6 \\
Fósforo assimilável $\left(\mathrm{mg} \mathrm{kg}^{-1}\right)$ & 6 & \\
\hline
\end{tabular}

A semeadura foi realizada em 20 de setembro de 2005, em nove bandejas de isopor, com 128 células cada, com substrato comercial. A germinação deu-se a partir de 22 de setembro, tendo alcançado o máximo com cinco dias após a germinação. O transplante foi efetuado em 29 de setembro, quando as plantas apresentavam duas folhas definitivas, e o replantio, cinco dias após. Durante o período entre a semeadura até o estabelecimento da cultura, que aconteceu após quinze dias de plantado, irrigaram-se duas vezes ao dia, aplicando o correspondente a $100 \%$ da evaporação do tanque Classe "A", de modo a manter um teor de umidade adequado para garantir um bom pegamento das plantas. A adubação de cobertura teve início dez dias após o transplantio, sendo aplicados durante o ciclo da cultura, via fertirrigação, nitrogênio em forma de ureia $\left(120 \mathrm{~kg} \mathrm{ha}^{-1} \mathrm{de}\right.$ $\mathrm{N}$ ), potássio na forma de cloreto de potássio $\left(270 \mathrm{~kg} \mathrm{ha}^{-1}\right.$ de $\mathrm{K}_{2} \mathrm{O}$ para $100 \%$ da recomendação),

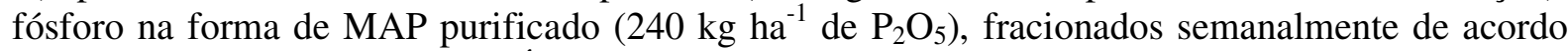
com as recomendações de CRISÓTOMO et al. (2002).

A irrigação foi diária, no período de 29 de setembro a 26 de novembro, e as lâminas de irrigação, estabelecidas de acordo com os tratamentos e baseadas na evaporação do tanque Classe "A", instalado na área. O tempo de irrigação para cada tratamento foi calculado com base na evaporação do tanque Classe "A", no espaçamento da cultura, na fração de molhamento (50\%), no número de emissores por planta e na vazão média dos emissores. A vazão do gotejador foi obtida através do catálogo do fabricante e comprovada através do teste de uniformidade de distribuição dos emissores, utilizando-se a metodologia descrita por KELLER \& KARMELLI (1975). Durante quinze dias iniciais, contados desde a semeadura, todos os tratamentos receberam as mesmas lâminas de irrigação, correspondentes à lâmina evaporada do tanque Classe "A". Isso teve por finalidade obter uma uniformidade do estande. A partir do $15^{\circ}$ dia, deu-se a diferenciação das lâminas de irrigação, de acordo com os tratamentos, a qual se deu até o $65^{\circ}$ dia, quando foi suspensa a irrigação do experimento.

Aos 66 dias após a semeadura, avaliou-se a produtividade, o peso médio do fruto e a eficiência do uso da água. Para a determinação do peso médio do fruto e da produtividade, o 
equipamento utilizado foi uma balança de precisão. A determinação da eficiência do uso da água (EUA) foi obtida pelo coeficiente entre o rendimento da cultura e a lâmina total de água aplicada durante o ciclo da cultura, segundo a equação abaixo.

$$
\mathrm{EUA}=\frac{\mathrm{Y}}{\mathrm{W}}
$$

em que,

EUA - eficiência do uso da água, $\mathrm{kg} \mathrm{ha}^{-1} \mathrm{~mm}^{-1}$;

$\mathrm{Y}$ - rendimento da cultura, $\mathrm{kg} \mathrm{ha}^{-1}$, e

W - lâmina total de água aplicada durante o ciclo, $\mathrm{mm}$.

Os resultados das características avaliadas foram analisados estatisticamente através de análise de variância com teste F. Quando significativos, foram submetidos à análise de regressão, buscando-se ajustar equações, através do software "SAEG - UFV 9.0", sendo selecionado o modelo de melhor nível de significância e o coeficiente de determinação $\left(\mathrm{R}^{2}\right)$.

\section{RESULTADOS E DISCUSSÃO}

A produtividade foi influenciada significativamente com o aumento da lâmina de irrigação avaliada para a produtividade; entretanto, não houve significância para a variável adubação potássica. O resultado observado no presente trabalho difere de SOARES (2001) que observou aumento linear, de VASQUEZ (2003), que observou aumento polimonial, e de OLIVEIRA et al. (2008) que observou aumento quadrático para a produtividade, com o incremento das lâminas de irrigação e adubação potássica na cultura do melão. A maior produtividade foi verificada com a aplicação da maior lâmina de irrigação (150\% ECA), seguida pelo tratamento $\mathrm{L}_{3}(100 \% \mathrm{ECA})$. Em contrapartida, o rendimento proporcionado pela menor lâmina aplicada foi inferior aos demais, porém não diferiu dos tratamentos 1 e $2(50 \%$ e $75 \%$ ECA) a 1\%, respectivamente. Com o aumento das lâminas de irrigação, houve aumento linear na produtividade (Figura 1), até a maior lâmina estimada de $150 \%$ da evaporação, correspondente à produtividade de $34,8 \mathrm{Mg} \mathrm{ha}^{-1}$.

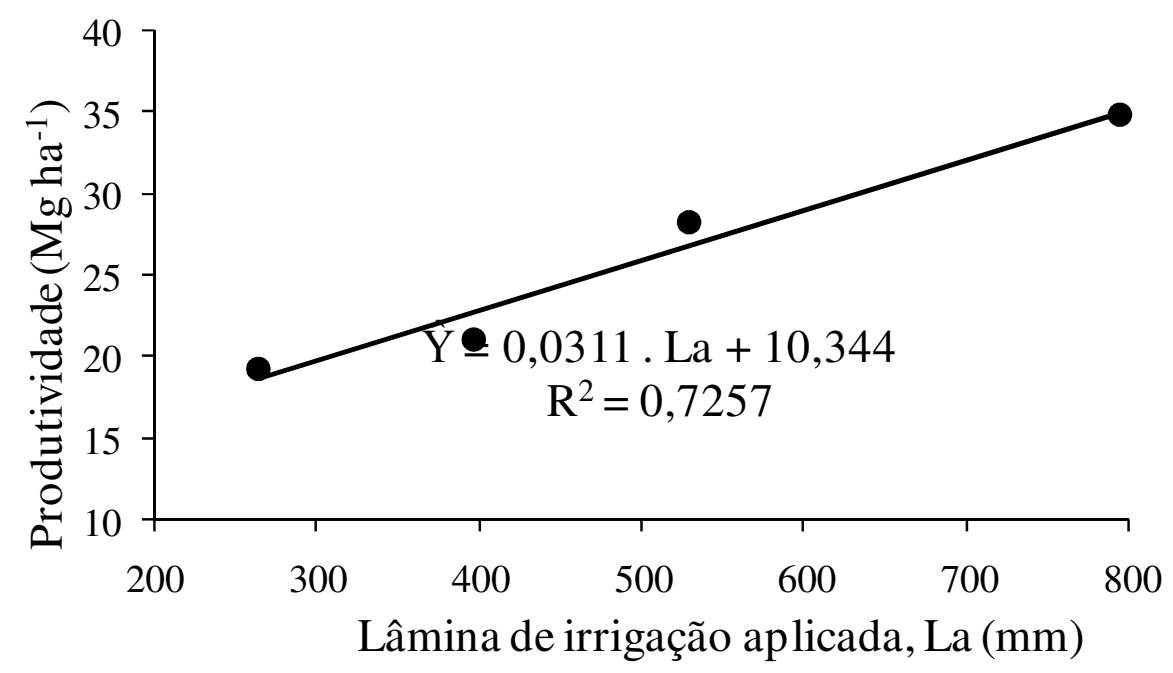

FIGURA 1. Produtividade de melão em função de lâminas de irrigações aplicadas. Melon production in function of applied irrigation blades.

Nas condições em que se deram os ensaios, verifica-se que o híbrido Gold Mine AF 10.00 alcança uma produtividade máxima de quase $35 \mathrm{Mg} \mathrm{ha}^{-1}$, sob lâmina de irrigação equivalente a $150 \%$ da ECA. $\mathrm{O}$ incremento observado na produtividade entre a menor e a maior lâmina de irrigação foi de $82 \%$, sendo que a amplitude foi superior a $16 \mathrm{Mg} \mathrm{ha}^{-1}$. Os resultados obtidos legitimam a posição de SANCHES \& DANTAS (1999), que afirmaram que a irrigação acarreta um aumento na produtividade 
das culturas, favorecendo os processos de crescimento, floração e frutificação da planta. De acordo com SANTOS (2006), o decréscimo de água no solo diminui o potencial de água na folha e sua condutância estomática, promovendo o fechamento dos estômatos. Esse fechamento bloqueia o fluxo de $\mathrm{CO}_{2}$ para as folhas, afetando o acúmulo de fotoassimilados, o que pode reduzir a produtividade. Por outro lado, a planta responde positivamente às condições mais favoráveis de água no solo, mantendo taxas fotossintéticas elevadas, proporcionando maior produção de fotoassimilados, implicando maiores produtividades.

Resultado divergente do verificado neste trabalho foi obtido em pesquisa com outra espécie da família curcubitácea, como a melancia. BASTOS (2004) encontrou resultado quadrático negativo na produtividade da melancia em função dos níveis de irrigação de $25 ; 50 ; 75 ; 100$ e $125 \%$ da evaporação do tanque Classe "A" no Distrito de Irrigação Jaguaribe Apodi, em Limoeiro do Norte - CE. Em contrapartida, MORAIS (2004) verificou aumento polinomial para a produtividade média da melancia em função dos níveis de irrigação de 50; 75; 100 e 150\% da evaporação do tanque Classe "A”, no Perímetro Curu, em Pentecoste - CE.

Vários autores têm sido unânimes ao comprovar os efeitos benéficos da aplicação de lâminas de 50 a $150 \%$ ECA, sobre a produtividade das curcubitáceas. A produtividade variou significativamente com o aumento da lâmina de irrigação, de acordo com a análise de variância, para o parâmetro peso médio do fruto de melão; observou-se que não houve significância para a variável adubação potássica e a interação dos fatores, porém foi significativa à lâmina de irrigação para o peso médio do fruto. Esse resultado difere do encontrado por SALES (2003) e VASQUEZ (2003), que não verificaram influência significativa da lâmina de irrigação aplicada para a cultura do meloeiro. Houve aumento exponencial quadrático do peso médio dos frutos com o aumento das lâminas de irrigação (Figura 2), até a maior lâmina estimada de $150 \%$ da evaporação, correspondente a uma produtividade de $34,8 \mathrm{Mg} \mathrm{ha}^{-1}$. O menor valor do peso médio do fruto corresponde ao tratamento $\left(\mathrm{L}_{1}: 50 \%\right.$ ECA) com $1,610 \mathrm{~kg}$ e o maior valor do peso médio ao tratamento $\left(\mathrm{L}_{4}: 150 \% \mathrm{ECA}\right)$ com $2,606 \mathrm{~kg}$.

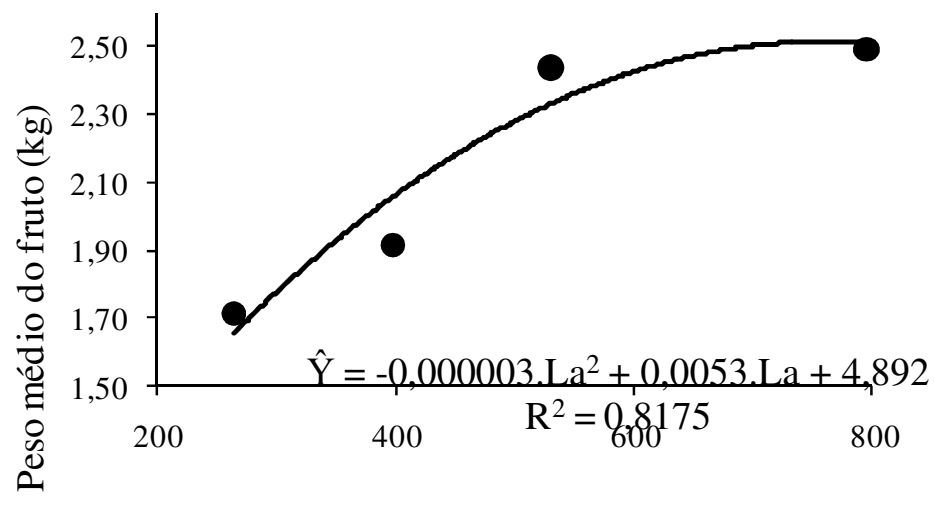

Lâmina de irrigação aplicada (mm)

FIGURA 2. Peso médio do fruto do melão em função das lâminas de irrigações aplicadas. Melon average weight in function of applied irrigation blades.

Relacionando-se a produtividade média com as lâminas de irrigação, referente a cada tratamento, tem-se a eficiência do uso da água. Na Tabela 3, podem-se observar esta eficiência e a sua variação percentual em relação ao menor valor.

As lâminas totais de água aplicadas nos tratamentos variaram de $795 \mathrm{~mm}\left(\mathrm{~L}_{4}\right)$ a $265 \mathrm{~mm}\left(\mathrm{~L}_{1}\right)$. Observa-se que, na medida em que a lâmina aumentou, a produtividade também aumentou, com incrementos relevantes, porém entre as lâminas $\mathrm{L}_{2}$ e $\mathrm{L}_{1}$ houve menor incremento, que pode ser 
traduzido numa redução das quantidades produzida para cada milímetro de água aplicado, ou seja, menor a eficiência de água utilizada.

TABELA 3. Eficiência do uso da água para a cultura do meloeiro. Efficient water use for melon cultivation.

\begin{tabular}{cccc}
\hline $\begin{array}{c}\text { Lâmina de Irrigação } \\
(\mathrm{mm})\end{array}$ & $\begin{array}{c}\text { Produtividade } \\
\left(\mathrm{kg} \mathrm{ha}^{-1}\right)\end{array}$ & $\begin{array}{c}\text { Eficiência do Uso da } \\
\text { Água }\left(\mathrm{kg} \mathrm{mm}^{-1}\right)\end{array}$ & $\begin{array}{c}\text { Variação Percentual } \\
(\%)\end{array}$ \\
\hline $795,0\left(\mathrm{~L}_{4}\right)$ & $34.779,00$ & 43,75 & - \\
$530,0\left(\mathrm{~L}_{3}\right)$ & $28.255,19$ & 53,31 & 21,85 \\
$397,5\left(\mathrm{~L}_{2}\right)$ & $21.777,80$ & 54,79 & 24,96 \\
$265,0\left(\mathrm{~L}_{1}\right)$ & $19.781,13$ & 74,65 & 61,20 \\
\hline
\end{tabular}

Para uma redução de $100 \%$ da maior para a menor lâmina, houve aumento da ordem de $61,2 \%$ da eficiência de uso da água. Estes resultados mostram que eficiência parecida foi encontrada por AZEVEDO (2004) na cultura da banana e por MORAIS (2004) na cultura da melancia, ambos no Vale do Curu, em Pentecoste - CE.

\section{CONCLUSÕES}

Os resultados obtidos demonstram que a utilização de maiores lâminas de irrigação aumentou a produtividade.

As doses de adubação potássica não alteram o rendimento, a produtividade e o peso médio do fruto, sendo necessária realização de estudos com maior amplitude das doses de potássio.

\section{AGRADECIMENTOS}

Ao CNPq, pelo apoio financeiro (projeto de pesquisa $n^{\circ} 470984 / 2003-1$ ) para a execução do experimento, e à FUNCAP, pelo apoio financeiro por meio da concessão de bolsa de estudos.

\section{REFERÊNCIAS}

AZEVEDO, J.H.O. de. Resposta de cultivares de banana (Musa sp) a quatro lâminas de irrigação no Município de Pentecoste - CE. 2004. 49 f. Dissertação (Mestrado em Irrigação e Drenagem) Centro de Ciências Agrárias, Universidade Federal do Ceará, Fortaleza, 2004.

BASTOS, F.G.C. Efeitos de níveis de irrigação, de doses de nitrogênio e de espaçamentos na cultura da melancia. 2004. 62 f. Dissertação (Mestrado em Irrigação e Drenagem) - Centro de Ciências Agrárias, Universidade Federal do Ceará, Fortaleza, 2004.

CARVALHO, L.C.C. de. Evapotranspiração e coeficientes de cultivo do melão sob diferentes lâminas de irrigação. 2006. 73 f. Tese (Doutorado em Irrigação e Drenagem) - Universidade Federal do Ceará, Fortaleza, 2006.

CRISÓSTOMO, L.A.; SANTOS, A.A dos; RAIJ, B.V; FARIA, C.M.B de; SILVA, D.J. da; FERNANDES, F.A.M.; SANTOS, F.J.S.; CRISÓSTOMO, J.R.; FREITAS, J. de A.D. de; HOLANDA, J.S. de; CARDOSO, J.W.; COSTA, N.D. Adubação, irrigação, híbridos e práticas culturais para o meloeiro no nordeste. Fortaleza: Embrapa Agroindústria Tropical, 2002. 21 p. (Circular Técnica, 14).

DALIPARTHY, J.; BARKER, A.V.; MONDAL, S. S. Potassium fractions with other nutrients in crops: a review focusing on the tropics. Jornal of Plan Nutrition, Monticello, v.17, n.11, p.1.859-1.886, 1994.

FERNANDES, V.L.B. (Coord.). Recomendações de adubação e calagem para o Estado do Ceará. Fortaleza: Universidade Federal do Ceará, 1993. 248 p. 
KELLER, J.; KARMELI, D. Trickle irrigation design. Glendora: Rain bird Sprinkler Manufacturing Corporation, 1975. 133 p.

MALAVOLTA, E. Potássio: absorção, transporte e redistribuição na planta. In: YAMADA, T.;

ROBERTS, T. L. (Ed.). Potássio na agricultura brasileira. Piracicaba: Associação Brasileira para Pesquisa da Potassa e do Fosfato, 2005. cap.8, p.179-238.

MARTINS, D.P. Resposta do maracujazeiro-amarelo (Passiflora edulis sims flavicarpa Dep) a lâminas de irrigação e doses de nitrogênio e potássio. 1998. 84 f. Tese (Doutorado) - Universidade Estadual do Norte Fluminense, Campos dos Goytacazes, 1998.

MORAIS, N.B. Rendimento da cultura da melancia em função dos níveis de água e adubação nitrogenada nas condições edafoclimáticas do Vale do Curu - CE. 2004. 66 f. Dissertação (Mestrado em Irrigação e Drenagem) - Universidade Federal do Ceará, Fortaleza, 2004.

NACHTIGALL, G.R.; RAIJ, B.V. Análise e interpretação do potássio no solo. In: YAMADA, T.; ROBERTS, T.L. (Ed.). Potássio na agricultura brasileira. Piracicaba: Associação Brasileira Para Pesquisa da Potassa e do Fosfato, 2005. cap.8, p.179-238.

OLIVEIRA, F. de A. de; MEDEIROS, J.F. de.; LIMA, C.J.G.S. de.; DUTRA, I.; OLIVEIRA, M.K.T. de. Eficiência agronômica da fertirrigação nitrogenada e potássica na cultura do meloeiro nas condições do semiárido nordestino. Caatinga, Mossoró, v.21, n.5, p.5-11, 2008.

SALES, I. G. M. Doses de potássio aplicadas via fertirrigação, por gotejamento superficial e subsuperficial, no meloeiro cultivado em ambiente protegido 2003. 73 f. Dissertação (Mestrado em Irrigação e Drenagem) - Universidade Federal do Ceará, Fortaleza, 2004.

SANCHES, N.F.; DANTAS, J.L.L. O cultivo do mamão. Cruz das Almas: EMBRAPA, Mandioca e Fruticultura, 1999. 105 p. (Circular Técnica, 34).

SANTOS, F.S.S. dos. Efeitos de diferentes lâminas de irrigação e doses de nitrato de potássio, aplicadas via fertirrigação, sobre a cultura do mamão formosa. 2006. 64 f. Dissertação (Mestrado em Irrigação e Drenagem) - Universidade Federal do Ceará, Fortaleza, 2006.

SOARES, A.J. Efeito de três lâminas de irrigação e de quatro doses de potássio via fertirrigação no meloeiro em ambiente protegido. 2001. 81 f. Tese (Doutorado em Irrigação e Drenagem) Escola Superior de Agricultura “Luís de Queiroz", Universidade de São Paulo, Piracicaba, 2001.

VASQUEZ, M.A.N. Fertirrigação por gotejamento superficial e subsuperficial no meloeiro (Cucumis melo L.) sob condições protegidas. 2003. 174 f. Tese (Doutorado em Irrigação e Drenagem) - Escola Superior de Agricultura "Luiz de Queiroz", Universidade de São Paulo, Piracicaba, 2003. 